\title{
The use of Sentinel-2 MSI data in small island's nearshore benthic habitat mapping
}

\author{
Muhammad Afif Fauzan ${ }^{1}$ \\ ${ }^{1}$ Cartography and Remote Sensing Undergraduate Program, Department of Geographic \\ Information Science, Faculty of Geography, Universitas Gadjah Mada, Indonesia 55281 \\ Corresponding email: m.afif.fauzan@mail.ugm.ac.id
}

\begin{abstract}
Maps of nearshore marine habitat are vital for coastal management and conservation. While traditional field mapping techniques are still commonly used, airborne and satellite remote sensing have proven to be efficient alternatives for creating benthic habitat maps. This paper evaluates the capability of new satellite data, Sentinel-2 MSI, to map nearshore benthic habitat of Derawan Island. Available aerial photographs were used as reference data. The results show that Sentinel-2 MSI data can be used to map benthic habitat with accuracy up to $75 \%$.
\end{abstract}

Keywords: Remote sensing, Sentinel-2 MSI, Derawan, benthic habitat mapping

\section{INTRODUCTION}

Nearshore marine habitats such as seagrasses and coral reefs have significant impacts on ecosystem by protecting coastal area, absorping carbon from atmosphere, and providing shelter and nutrients for many marine organisms ${ }^{[1]}$. However, these resources are in decline due to anthropogenic activities such as coastal area development ${ }^{[2]}$, unsustainable fishing practices ${ }^{[1]}$, and poor watershed management which leads to excessive nutrient loads and sediment run-off and affect water quality. Natural factor such as megaherbivore grazing may also responsible for habitat destruction, as reported in Derawan Archipelago, where seagrass beds are overgrazed by increasing population of green turtles ${ }^{[3]}$.

In order to preserve the remaining habitats, there is a growing need to provide spatially explicit information on the distribution of nearshore marine habitats. Those information are vital to their conservation and management ${ }^{[4]}$, which also can be viewed as an effort to support the Goal 14 of Sustainable Development Goals (SDG) to conserve oceans, seas, and marine resources for sustainable development.
For decades, remote sensing data from various platforms and sensors have been used in mapping and monitoring nearshore benthic habitat because of its cost-effectiveness and large area coverage $^{[4]}$. Recently, a new earthobservation satellite, Sentinel-2A, was launched as part of Copernicus program. The satellite carries multi-spectral imager sensor (MSI) on board, delivering free high-spatial resolution $(10 \mathrm{~m})$ images data on visible and near-infrared spectrum, which is very potential for benthic habitat mapping in archipelago country such as Indonesia.

To date, there is no specific results have been published evaluating Sentinel-2 MSI images for benthic habitat mapping in tropical region. This study assessed the capability of Sentinel-2 MSI data for mapping benthic habitat in nearshore of Derawan Island.

\section{METHODS}

Study Area

This study is located at nearshore of Derawan Island, Berau, East Kalimantan, Indonesia (Figure 1). The island is located $18 \mathrm{~km}$ from the mainland, and was established as marine protected 
area (MPA $)^{[3]}$. The benthic habitats occur in fringing reef, where submerge sandy substrate are partly covered by seagrass meadows. This island is a tourism destination and also habitat for endangered green sea turtle, which are fully protected in this MPA. Consequently, there is an increasing trend of green turtle population density, followed by degraded seagrass habitat due to green turtle overgrazing phenomenon $^{[3]}$.

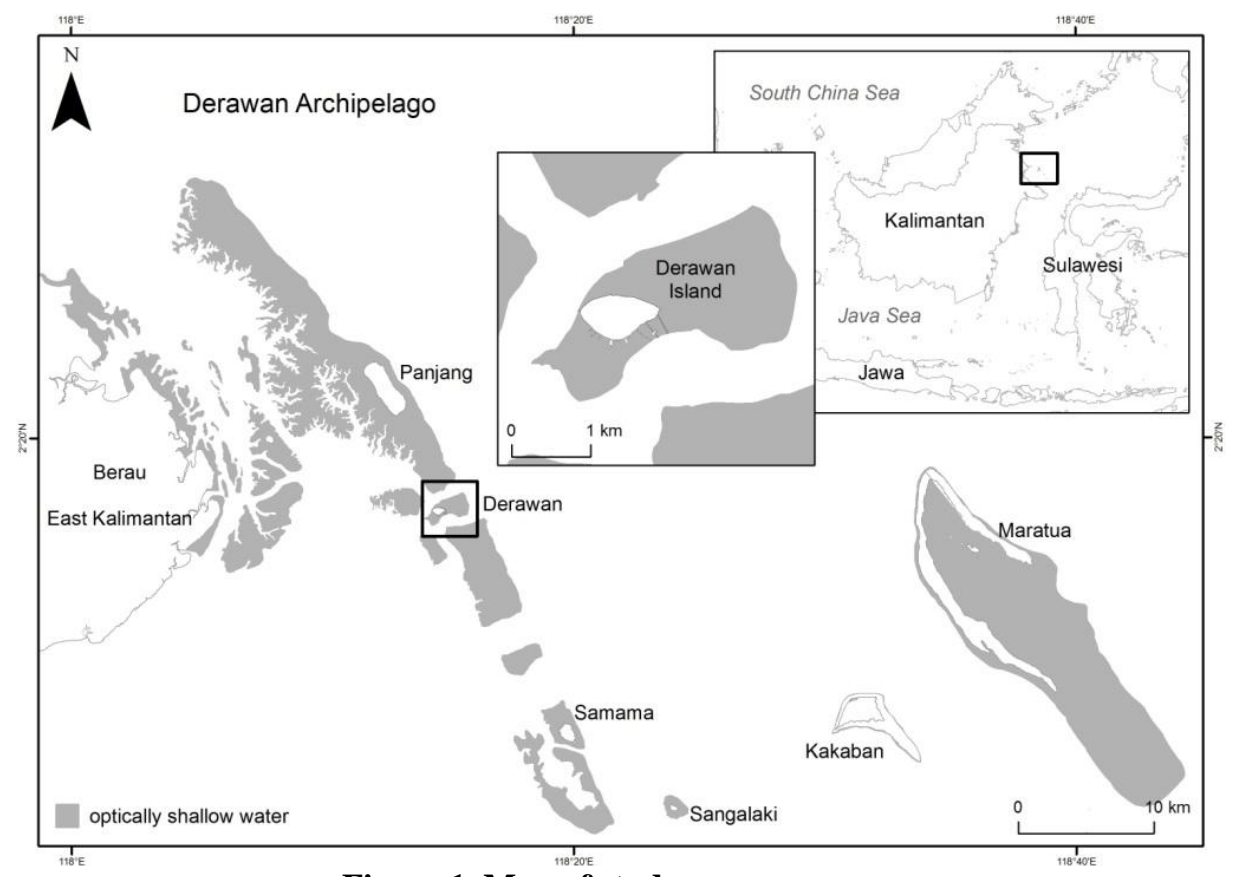

Figure 1. Map of study area.

\section{Satellite and Aerial Images}

Sentinel-2 MSI images acquired on June 7th, 2016 were obtained from Sentinels Scientific Data Hub (http://scihub.copernicus.eu/dhus) on Level-1C (L1C) top-of-atmosphere reflectance. Atmospheric correction was applied to the data using DOS-1 module provided in Semi-Automatic Classification Plugin on QGIS 2.14 software to retrieve water surface reflectance. In addition, Depth-Invariant Bottom Index (DII) was performed to compensated water column effect on benthic object reflectance ${ }^{[5]}$.

Unmanned aerial vehicle (UAV) was used to collect aerial photographs (AP) around Derawan Island. The AP were taken on approximately $250 \mathrm{~m}$ altitude on February 2012 during cloudy weather to minimize the wave reflection. This very high-resolution image permits visual interpretation (Figure 2) and can provide detail data that can be used as reference data ${ }^{[6,7]}$ for classification input and accuracy assessment for resulting benthic habitat maps.

\section{Classification and Accuracy Assessment \\ The maximum likelihood} classifier (max-like) is the one of the most popular classification algorithm in benthic habitat mapping using remotely sensed data ${ }^{[8,9]}$. This algorithm was performed to original bands and DII bands. Prior to classification, random points were generated, and corresponding pixel from natural color composite (NCC) image, combined with AP, were visually interpreted to determined calibration samples and validation samples. Confusion matrix ${ }^{[10]}$ was used to assess the accuracy of resulting maps. A total of 116 and 29 samples were collected for training and validation data, respectively.

\section{RESULT AND DISCUSSION}

Benthic habitat maps derived from both original bands and DII bands have a high degree of correspondence to the reference AP and image features (Figure 3 ). Based on both maps, submerged sand 


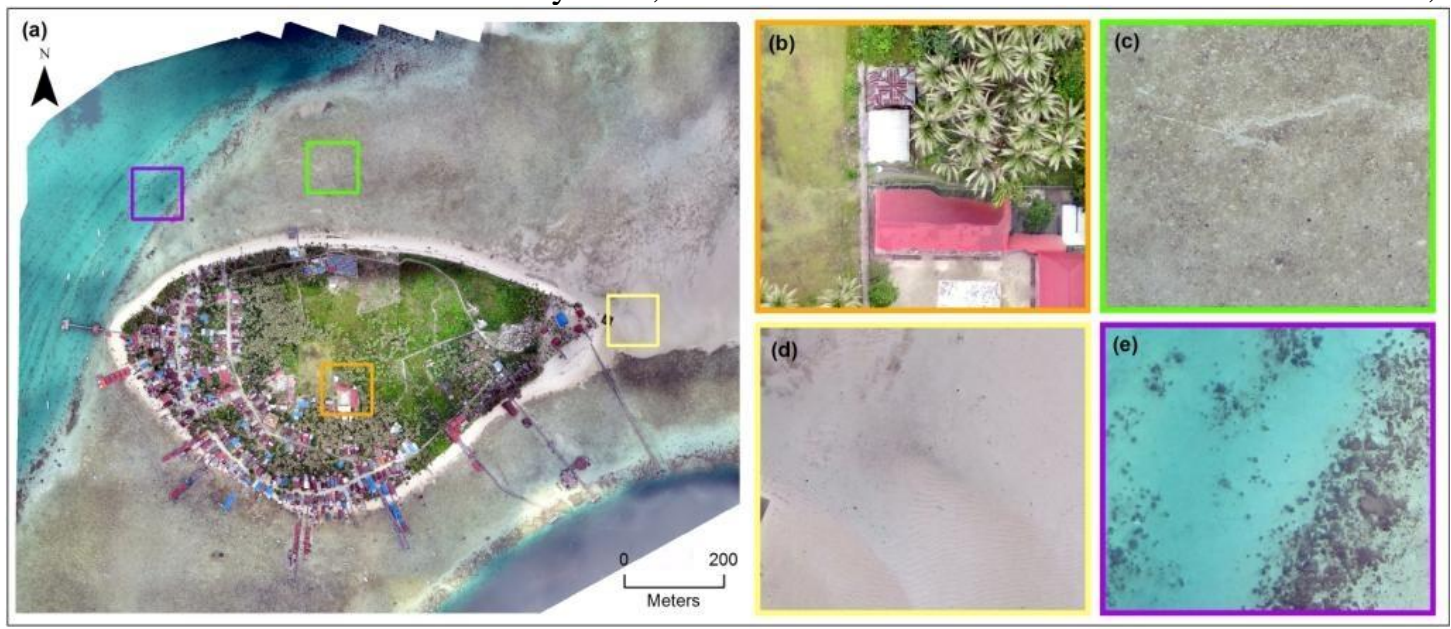

Figure 2. (a) AP of Derawan Island as reference data (taken by Christianen, see acknowledgements). (b) Land objects which was not included in analysis. (c) Seagrasses. (d) Submerged sand. (e) Coral reefs.

which is deeper and the closest to the open sea. The most noticable difference from both maps is seagrass class, which in map derived from DII bands occurs in larger area than in map derived from original bands. This class area, however, looked relatively underestimated when compared to NCC or AP relatively by visual appearance.

According to Christianen ${ }^{[3]}$, seagrass in this area are dominated by Halodule uninervis species. This species has small leaves, thus not significantly covering the sandy bottom where they grow. Therefore, remote sensor will record the reflectance signal as reflectance from seagrasses and its sandy background, generalized in a pixel unit, known as mixed pixel. This issue often happened in the environment where seagrass beds are sparse and have low percent cover ${ }^{[11]}$. The sparse seagrass beds, therefore, classified as the substrate underlying it, while the dense seagrass beds classified as seagrass class. The inability of the data to separate spectral signature of seagrass and sand is illustrated in the error matrix table where seagrass and submerged sand being misclassified to each other class (Table 1).

Overall, map derived from DII bands has higher producer and user accuracy for each classes target, and also higher overall accuracy $(75.86 \%)$ and kappa coefficient, compared to map derived from original bands (58.62\%).
This result suggests that DII transformation can enhance the information of spectral reflectance from benthic object in the image, thus, improving the accuracy of the classification result.

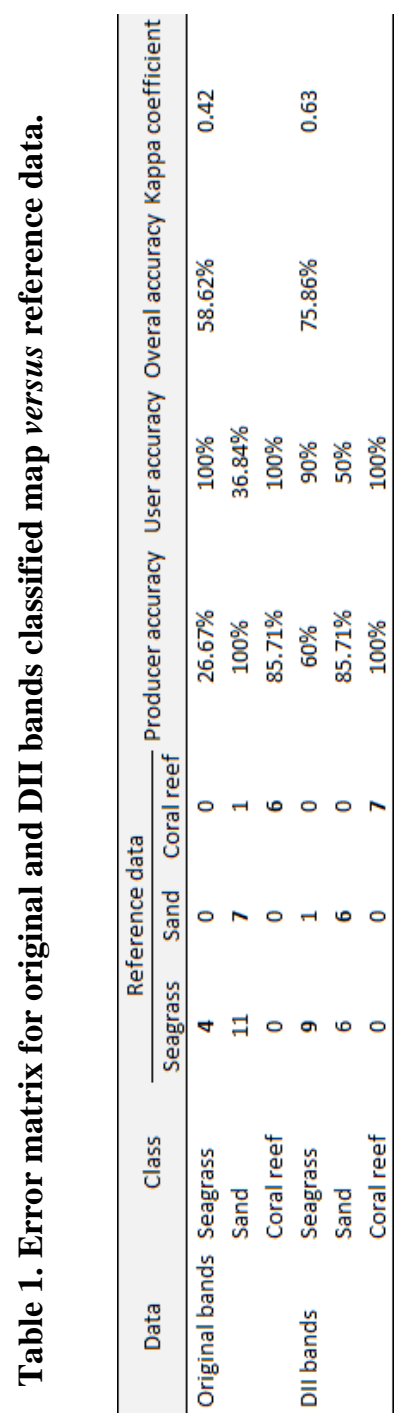




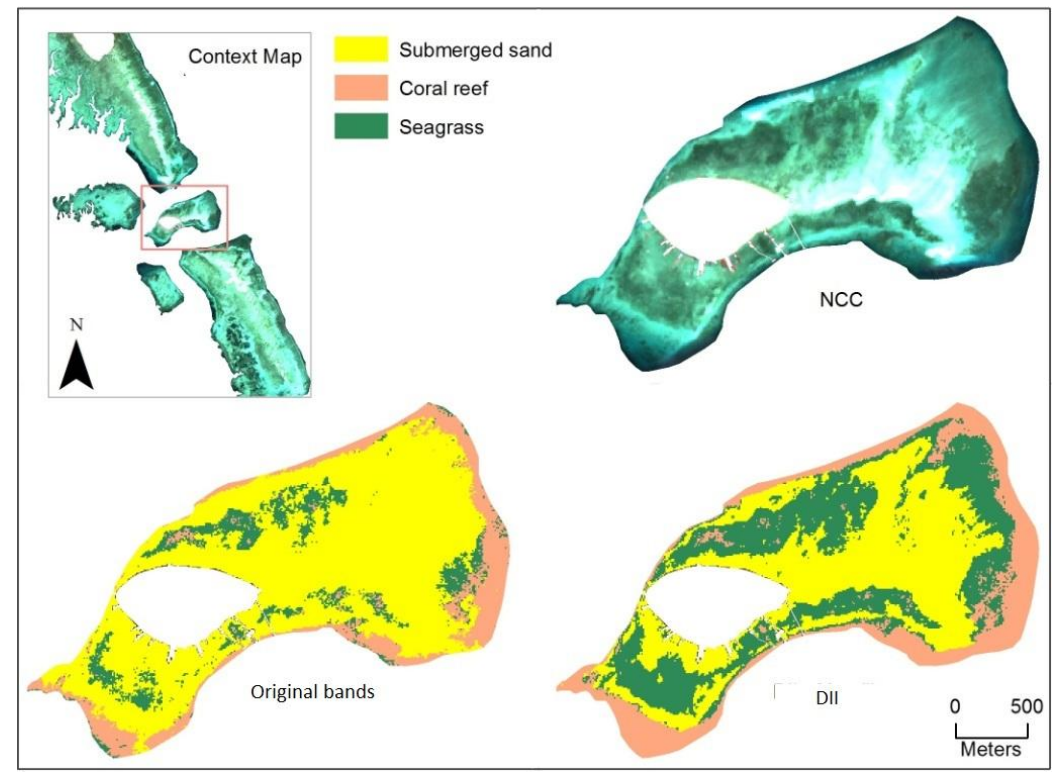

Figure 3. Map of classification results.

\section{CONCLUSION}

This study demonstrated the ability of Sentinel-2 MSI data for benthic habitat mapping using aerial photographs as in-situ data with different mapping inputs. Overall, the data and algorithm mapped the target classes with moderate accuracy. The results show that aerial photographs could replace in-situ data, and by applying image-based water column correction such as DII, improvement of mapping accuracy was obtained.

For future research, a larger study area and more robust water column correction could be used. Future research should also address feature extraction of specific benthic object such as seagrass from different period image when there is no or limited in-situ data available. These information could be useful in understanding the dynamics of seagrass ecosystem under pressure from green turtle overgrazing and coastal development for tourism in Derawan Archipelago.

\section{CONFLICT OF INTEREST} interest.

Author declares no conflict of

\section{ACKNOWLEDGEMENTS}

Author would like to thank Dr. Pramaditya Wicaksono (Universitas Gadjah Mada) for the discussions in remote sensing for benthic habitat mapping, and Dr. Marjolijn J. A.
Christianen (University of Groningen, Netherlands) for providing information of the study area and aerial photographs used in this study.

\section{REFERENCES}

[1] Orth RJ, Carruthers TJB, Dennison WC, Duarte CM, Fourqurean JW, Heck Jr. KL, Hughes R, Kendrick GA, Kenworthy WJ, Olyarnik S, Short FT, Waycott M, William SL. 2006. A global crisis for seagrass ecosystems. BioScience, 56(12), 987996.

[2] Hutomo M \& Moosa MK. 2005. Indonesian marine and coastal biodiversity: Present status. Indonesian Journal of Marine Sciences, 34(1), 88-97.

[3] Christianen MJA, Herman MJP, Bouma TJ, Lamers LP., van Katwijk MM, van der Heide T, Mumby PJ, Siliman BR, Engelhard, van de Kark M, Kiswara W, van de Koppel J. 2014. Habitat collapse due to overgrazing threatens turtle conservation in marine protected areas. Proceedings of The Royal Society B: Biological Science, 1-7.

[4] Green EP, Mumby PJ, Edwards AJ, Clarck CD. 2000. Remote Sensing Handbook for Tropical Coastal Management. Coastal Management 
Sourcebook 3. (AJ Edwards, Ed.). UNESCO Paris.

[5] Lyzenga DR. 1981. Remote sensing of bottom reflectance and water attenuation parameters in shallow water using aircraft and Landsat data. International Journal of Remote Sensing, 2, 71-82.

[6] Campbell JB \& Wynne RH. 2011. Introduction to Remote Sensing, 5th Edition. The Guildford Press.

[7] Lyons MB, Phinn SR, Roelfsema CM. 2012. Long term land cover and seagrass mapping using Landsat and object-based image analysis from 1972 to 2010 in the coastal environment of South East Queensland, Australia. ISPRS Journal of Photogrammetry and Remote Sensing, 71, 34-46.

[8] Blakey T, Melesse A, Hall MO. 2015. Supervised classification of benthic reflectance in shallow subtropical waters using a generalized pixel-based classifier across a time series. Remote Sens, 7, 5098-5116.

[9] Sagawa T, Boisnier E, Komatsu T, Mustapha KB, Hattour A, Kosaka N, Miyazaki S. 2010. Using bottom surface reflectance to map coastal marine areas: a new application method for Lyzenga's model. International Journal of Remote Sensing, 31(12), 3051-3064.

[10] Congalton RG, Green K. 2009. Assessing the Accuracy of Remotely Sensed Data: Principles and Practices. CRC Press.

[11] Krause-Jensen D, Quaresma AL, Cunha AH, Greve TM. 2004. How are seagrass distribution and abundance monitored? In J Borum, CM Duarte, D Krause-Jensen, \& TM Greve (Eds). In European seagrasses: an introduction to monitoring and management. The M\&MS project. 